\title{
Low back pain, obesity, and inflammatory markers: exercise as potential treatment
}

\author{
Isabela Maia da Cruz Fernandes ${ }^{1, *}$, Rafael Zambelli Pinto², Paulo Ferreira ${ }^{3}$, Fábio Santos Lira ${ }^{1}$ \\ 'Exercise and Immunometabolism Research Group, Department of Physical Education, Faculty of Sciences and Technology, São Paulo State University, Presidente Prudente, \\ São Paulo, Brazil \\ ²Department of Physical Therapy, Universidade Federal de Minas Gerais (UFMG), Belo Horizonte, Brazil \\ ${ }^{3}$ Discipline of Physiotherapy, The University of Sydney - Faculty of Health Sciences, Sydney, Australia
}

Low back pain is a health issue with significant impact to patients and society. This narrative review aims to synthesize the relationship between obesity, low-grade inflammation and low back pain. It is known that a sedentary lifestyle is a risk factor for obesity and related disorders. The adipose tissue of obese people secretes a range of cytokines of character pro- and anti-inflammatory, with many molecular effects. In addition, pro-inflammatory cytokines are sensitizers of $\mathrm{C}$-reactive protein (CRP), a marker of acute inflammation that can be linked to the musculoskeletal pain sensation individuals with back pain. Another inflammatory marker deserves mention, prostaglandin $\mathrm{E}_{2}$. Prostaglandin $E_{2}$ is important in the process of triggering actions such as pyrexia, sen- sation of pain and inflammation, which are exhibited in low back pain condition. The potential for exercises and physical activity to control these mediators and act as a preventative measure for back pain are important because they work as a nonpharmacological strategy to this target audience. There are two types of exercise discussed in this review, the moderate-intensity continuous training and high-intensity interval training.

Keywords: Low back pain, Obesity, Sedentary lifestyle, C-reactive protein, Prostaglandins

\section{INTRODUCTION}

Low back pain is an extremely common health problem and its economic burden increases every year (Briggs et al., 2011; Hoy et al., 2010a; Hoy et al., 2010b). Despite the condition being widely documented in the literature, its etiology, effective management, and prognosis still require further investigation. The goal of this brief review is to summarize the importance of chronic low-grade inflammation in low back pain and show measures capable of mitigate these problems.

\section{PREVALENCE}

The prevalence of low back pain has grown over the years, while the incidence of low back pain affects mainly mid to older people and females (Briggs et al., 2013; Hoy et al., 2010a; Manchikanti et al., 2014; Stewart Williams et al., 2015; Teichtahl et al., 2015; Zanuto et al., 2015). Of note, low back pain is also a prevalent health problem in Brazil. In a recent population study in the city of Presidente Prudente - Brazil, the prevalence of reported back pain in the last year was $50.2 \%$, and $32.3 \%$ in the last week ( $\mathrm{Za}$ nuto et al., 2015). Another population study involving elderly residents of São Paulo - Brazil, the prevalence of low back pain was $29.7 \%$ and almost half of this (49.6\%) reported low back pain with moderate intensity and events occurring with daily attendance (Dellaroza et al., 2013). The factors that influence the prevalence and incidence of low back pain include associated comorbidities such as depression and cardiovascular diseases, lifestyle factors (e.g., smoking), occupational and psychosocial factors, and physical inactivity (Ferreira et al., 2011; Manchikanti et al.,
${ }^{*}$ Corresponding author: Isabela Maia da Cruz Fernandes (iD) https://orcid.org/0000-0003-3347-7203

São Paulo State University - UNESP, Department of Physical Therapy, Rua Roberto Simonsen - 19060-900, Presidente Prudente, São Paulo, Brazil

Tel: +55-18-981451617, Fax: +55-18-32295388, E-mail: isabelamaia.cf@gmail.com Received: February 10, 2017 / Accepted: March 26, 2018
This is an Open Access article distributed under the terms of the Creative Commons Attribution Non-Commercial License (http://creativecommons.org/licenses/by-nc/4.0/) which permits unrestricted non-commercial use, distribution, and reproduction in any medium, provided the original work is properly cited. 
2014). In addition to environmental lifestyle factors, genetics has an important contribution in the prevalence of chronic low back pain (Junqueira et al., 2014).

\section{ETIOLOGY}

The high prevalence of low back pain may be explained by the fact that the condition is considered a multifactorial disease and therefore has several possible causes (Amirdelfan et al., 2014; Langevin and Sherman, 2007). A systematic review based on twin samples found a variety of factors that can be associated with low back pain (Ferreira et al., 2011). Among the factors listed the most significant ones were smoking, obesity or higher levels of body mass index (BMI), patients' self-assessment of poor health, comorbidities (asthma, diabetes, headache, osteoarthritis, and osteoporosis), physical workload, lower levels of physical activity, and depression (associated with physical disability). Further literature reviews (Amirdelfan et al., 2014) also list some factors that may be predictors of low back pain, such as problems in gastrointestinal tract, pelvic disorders, gynecological, vascular, and psychological issues. However, the cell molecular mechanism involved in the inflammatory process, or response in low back pain are poorly studied. Therefore, this manuscript aims to review the literature on the relationship between low back pain, obesity, and inflammatory markers.

\section{SEDENTARY LIFESTYLE}

Heneweer et al. (2009) found that sedentary lifestyle was associated with 1.41 times greater risk of developing back pain. In addition, people who do not comply with the current recommendation for physical activity ( $\geq 150$ min per week) have 1.23 times more chances to develop low back pain.

On the other hand, people involved in sport activities, particularly on level of 1-2.5 hr/wk, were less likely to develop chronic low back pain complaints (odds ratio [OR], 0.72: 95\% confidence interval [CI], 0.58-0.90). The intensity or type of sport did not affect the results (Heneweer et al., 2009). In a meta-analysis of 14 studies it was observed an inverse relationship between physical disability due to low back pain and physical activity, indicating that higher levels of disability correspond with lower levels of physical activity (OR, -0.33 ; 95\% CI, -0.51 to -0.15 ) (Lin et al., 2011). In summary, the practice of any physical activity may be a protective factor for the development of low back pain, except a very high level of physical activity, that can increase the risk of low back pain (Shiri et al., 2013). In a recent study (Teichtahl et al., 2015), the lowest level of physical activity was associated with an increased risk of disability and high intensity pain (OR, 5.0; 95\% CI, 1.5-16.4) after adjustment for age, sex and BMI. However, results also highlighted that people with high levels of physical activity had no symptoms of low back pain and disability (Teichtahl et al., 2015).

\section{OBESITY}

Since sedentary lifestyle and/or insufficient physical activity are associated with the incidence of low back pain and that they are independent risk factors for obesity development (Chen et al., 2009; Mikkonen et al., 2016; Teichtahl et al., 2015), it is expected that there is a close relationship between these outcomes. Supporting this idea, Dario et al. (2016) in a meta-analysis comprised of five studies investigating the association between obesity and low back pain, revealed that twins with high weight and BMI were nearly 2 times more likely to have low back pain compared to those with normal weight or below normal. Moreover, in this same study it was found that twins underweight had lower prevalence of low back pain than twins with normal BMI. However, environmental and genetic factors seem to interfere and act as a confounder in this relationship (Dario et al., 2015). Moreover, a recent study noted that $80.6 \%$ of the obese population investigated had low back pain, in contrast, to their corresponding low BMI the prevalence was less than 60\% (Ibrahimi-Kaçuri et al., 2015). Currently, obese and sedentary individuals constitute the most susceptible group to develop low back pain (Shiri et al., 2013).

\section{ADIPOSE TISSUE AND INFLAMMATORY MARKERS}

It is known that adipose tissue, currently considered an endocrine organ, when hypertrophied, is characterized by increased production of pro-inflammatory cytokines such as tumor necrosis

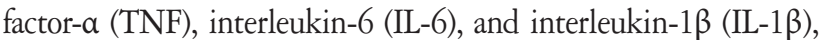
which may generate a frame of chronic low grade inflammation (Galic et al., 2010). Besides, obese individuals present high concentrations of C-reactive protein (CRP), an acute phase inflammatory marker mainly produced in the liver in response to IL-6 (Lau et al., 2005; Pepys and Hirschfield, 2003), compared to eutrophic individuals (Briggs et al., 2013; Dowd and Zajacova, 2014). The same has been reported as a predictor of cardiovascular risk (Esser et al., 2015). In addition to its pro-inflammatory function associ- 
ated with obesity, CRP has been classically described as extremely sensitive systemic marker of inflammation and tissue damage (Pepys and Baltz, 1983; Pepys and Hirschfield, 2003). This occurs, because the injured tissue recruits immune cells such as macrophages and neutrophils, which act on tissue healing. This outcome leads to increased local production of pro-inflammatory cytokines (TNF and IL-6) that are sensitizers of CRP production, especially in hepatocytes (Pepys and Hirschfield, 2003). According to research (Briggs et al., 2013), CRP may be present in signaling responsible for sensation or activation of the pain of musculoskeletal system. Stürmer et al. (2005) investigated CRP concentrations in patients with acute low back pain, but in different levels of severity (visual analogue scale, VAS). It was noted that category of people with greatest severity of low back pain ( $>4$ points - VAS) had higher CRP concentration $(1.3 \mathrm{mg} / \mathrm{L})$, while the category of less severity of pain $(\leq 2$ points - VAS) had lower CRP concentration $(0.8 \mathrm{mg} / \mathrm{L})$. Gebhardt et al. (2006) compared CRP levels in patients with acute and chronic low back pain for 6 months. At baseline, there were no statistically significant differences in concentrations of CRP in patients with acute low back pain $(1.49 \mathrm{mg} / \mathrm{L})$ when compared with CRP concentrations in patients with chronic low back pain $(1.30 \mathrm{mg} / \mathrm{L})$. However, it was found that, in the first 3 weeks of follow-up, the group of patients with acute low back pain showed a significant decrease of CRP concentrations $(1.49 \mathrm{mg} / \mathrm{L} \rightarrow 0.40 \mathrm{mg} / \mathrm{L})$ associated with outcomes pain and functional capacity. Whereas in chronic low back pain group CRP concentrations remained constant $(1.31 \mathrm{mg} / \mathrm{L} \rightarrow$ $1.39 \mathrm{mg} / \mathrm{L}$ ) and had no relationship with measures of pain and functional capacity. When combined, high CRP levels and obesity, the odds of reporting low back pain increased more than twice (OR, 2.87; 95\% CI, 1.18-6.96) (Briggs et al., 2013).

As aforementioned, CRP is an acute phase inflammatory marker (Lau et al., 2005; Pepys and Hirschfield, 2003). The literature describes also during the inflammatory process occurs the production of prostanoids - a group of eicosanoids produced by arachidonic acid (AA) (Sugimoto and Narumiya, 2007; Woodward et al., 2011). The AA can be generated from phospholipase (cleavage of cell membrane phospholipid) of the type A2 (Burke and Dennis, 2009), and/or omega-6 from our diet (Astudillo et al., 2012). This can follow two different routes to form eicosanoids: the route cyclooxygenase (COX) and lipoxygenase pathway (Smith and Murphy, 2002). As mentioned, the recruitment of macrophages at least in part, may contribute to the onset and progression of low back pain, promoting, in particular of activation of the COX (specifically, COX-2).

COX-2 is the pathway responsible for the production of prosta-

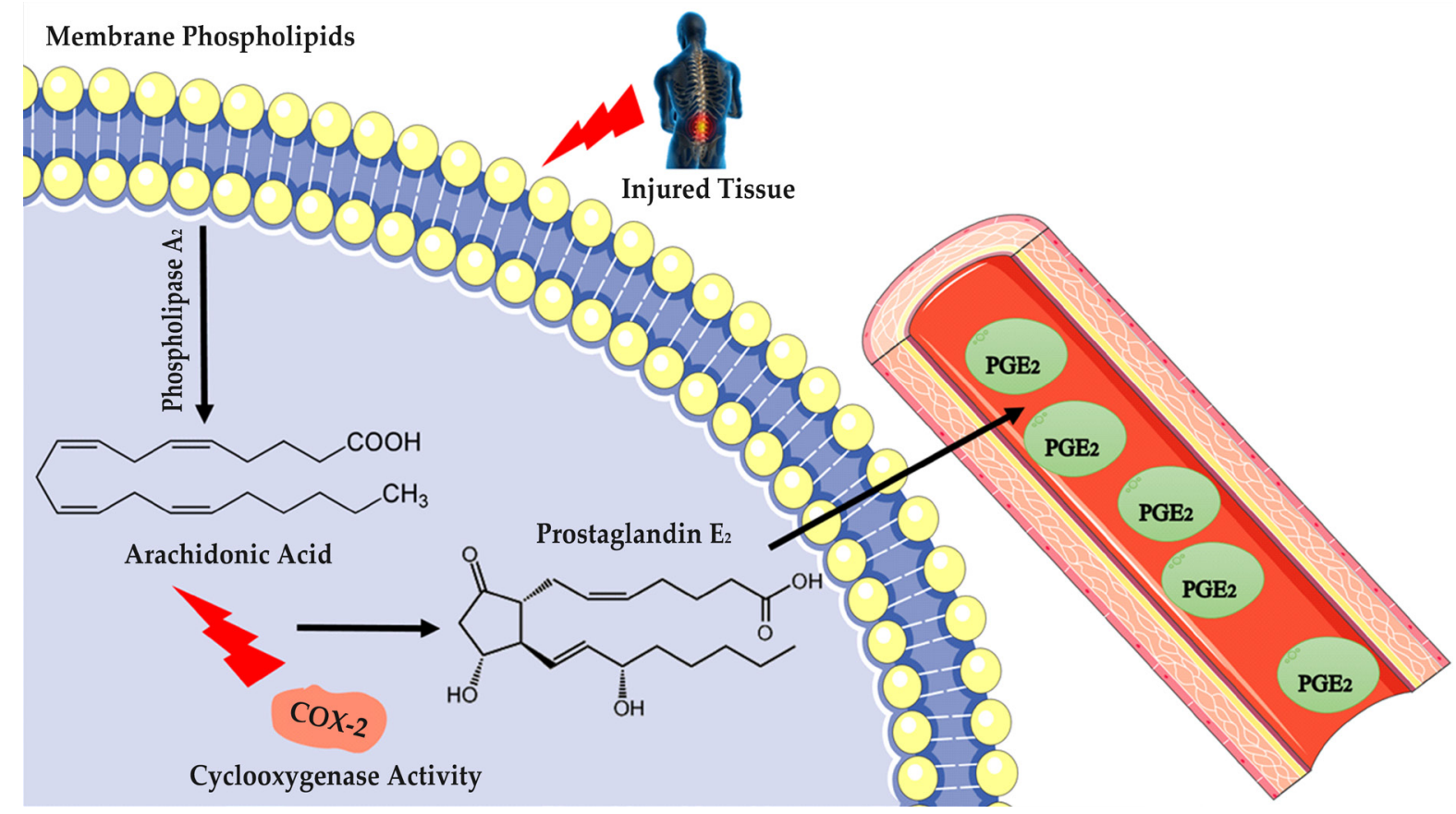

Fig. 1. From a tissue injury, such as low back pain, phospholipidic membrane will undergo a phospholipase $A_{2}$, yielding arachidonic acid. This polyunsaturated fatty acid, through the action of cyclooxygenase-2 enzyme, will produce numerous prostaglandins. COX-2, cyclooxygenase-2 enzyme; $\mathrm{PGE}_{2}$, prostaglandin $\mathrm{E}_{2}$. 
noids (Gomez et al., 2013; Smith et al., 2000). Prostanoids are constituted by four types of prostaglandins (PGs) and thromboxanes (TXs): $\mathrm{PGE}_{2}, \mathrm{PGD}_{2}, \mathrm{PGF}_{2}, \mathrm{PGI}_{2}$ and $\mathrm{TXA}_{2}$ (Smith et al., 2000; Smith and Murphy, 2002). In addition, PGs are produced by the sequential action of the COX-2 and their respective AA synthases, released by phospholipase $\mathrm{A}_{2}$ to phospholipid membrane (Fig. 1) (Sugimoto and Narumiya, 2007; Woodward et al., 2011).

\section{$\mathrm{PGE}_{2}$ AND EXERCISE}

$\mathrm{PGE}_{2}$ is important in the process of triggering actions such as pyrexia, sensation of pain and inflammation (Sugimoto and Narumiya, 2007; Woodward et al., 2011), which may be present in cases of low back pain in obese individuals, especially those who exhibit a frame chronic low-grade inflammation. Based on this, should be noticed that low back pain, obesity and chronic lowgrade inflammation are closely related, and interventions for mitigating these outcomes are important from the point of view of treatment.

The practice of physical exercise promotes a range of positive health changes, such as improvement in lipid profile, reducing chronic low-grade inflammation systemic and local, decreasing risk of developing obesity, diabetes mellitus 2 and cardiovascular diseases (Lira et al., 2010; Nimmo et al., 2013). Furthermore, regular exercise may be considered a form of nonpharmacological treatment for obesity, low back pain, and other chronic diseases (Neto et al., 2011).

A literature review (Nimmo et al., 2013) found that lifestyle modification can also reduce body fat, the main site of inflammatory proteins production. Indeed, involvement in physical exercise programs has an inverse relation with the development of chronic low-grade inflammation (Hawkins et al., 2012; Hsu et al., 2009).

\section{MODERATE-INTENSITY CONTINUOUS TRAINING}

Exercise in the form of continuous aerobic training is characterized by the performance of continuous contractile activity for long periods in light to moderate intensity ( 50\%-75\% maximum oxygen uptake $\left.\left[\mathrm{VO}_{2 \max }\right]\right)$. This can be performed in several intensities from very light $\left(<37 \%\right.$ of peak $\mathrm{VO}_{2}\left[\mathrm{VO}_{2 \text { peak }}\right]$ ) until a maximum intensity ( $\geq 91 \%$ of peak $\mathrm{VO}_{2}$ ) as suggested by Garber et al. (2011).

When it comes to continuous exercise, studies are well docu- mented. Gray et al. (2009) investigated the efficacy of an intervention performed for 12 weeks (walking - 3,000 steps per day, 5 times a week - monitored by a pedometer) in systemic inflammatory markers in overweight adults. In conclusion, the intervention did not promote reduction of circulating inflammatory markers such as CRP, IL-6, and TNF- $\alpha$. This finding corroborates with the study by Polak et al. (2006), which found no change in circulating inflammatory proteins (IL-6, TNF- $\alpha$ ) and anti-inflammatory (adiponectin) after submitting 25 sedentary and obese individuals on a 12 weeks of aerobic training program, with a frequency of 5 times per week, and moderate intensity $\left(50 \% \mathrm{VO}_{2 \text { peak }}\right)$. The training consisted of two supervised sessions per week of aerobic exercise and 3 sessions per week of exercise at home performed on a cycle ergometer. In addition, after 12 weeks of continuous moderate-intensity aerobic exercise intervention (energy expenditure of 500-600 kcal), 3 times/wk lasting 60-75 min, Christiansen et al. (2010) also found no change in circulating inflammatory proteins (IL-6, IL-15, IL-18, MCP-1, adiponectin and MIP1a). Libardi et al. (2012) showed that, despite improvements in lipid and glycemic profiles after continuous aerobic training (60 min of walking and running, with $55 \%-85 \%$ of $\mathrm{VO}_{2 \text { peak }}$, no significant change was observed in markers (IL-6, TNF- $\alpha$, and CRP) of chronic lowgrade inflammation. In contrast (Balducci et al., 2010), prescribed a continuous aerobic training for type 2 diabetic patients - performed 2 times/wk, $70 \%-80 \%$ of $\mathrm{VO}_{2 \text { peak }}$ for $60 \mathrm{~min}$ - and found its effectiveness in promoting an anti-inflammatory profile. The anti-inflammatory profile was characterized by an increase of adiponectin and a tendency to increased IL-10 and decrease TNF- $\alpha$, IL-6, and interferon-gamma. Moreover, the authors highlight the importance of long-term intervention (12 months).

\section{HIGH-INTENSITY INTERVAL TRAINING}

More recently, the adoption of aerobic training performed intermittently and high intensity programs has drawn attention from the scientific community, due to its effect on reducing fat deposits and improving aerobic capacity.

It has been demonstrated that high-intensity interval training (HIIT) has several clinical benefits to health of populations, and to improve their risk factors for chronic diseases (Gibala et al., 2012; Shiraev and Barclay, 2012). According to Gibala and McGee (2008) HIIT consists of work out repeatedly at a high intensity for $30 \mathrm{sec}$, separated by an interval of $1-$ to 5 -min recovery. This recover may remain at rest or performing an active rest. Leggate et al. (2012) conducted a study involving HIIT $\left(85 \% \mathrm{VO}_{2 \text { peak }}\right.$ ) and 
demonstrated, in just 2 weeks, beneficial changes in pro-inflammatory markers circulating and adipose tissue in obese individuals and males. Additionally, significant differences in body mass, percentage body fat, and waist circumference were demonstrated after HIIT (Ahmadizad et al., 2015). Weston et al. (2014) identified that HIIT has more physiological benefits than continuous training of moderate intensity in patients with diseases induced by lifestyle. HIIT improved nearly double the cardiorespiratory fitness $\left(\mathrm{VO}_{2 \max }\right)$ compared with continuous training (19.4\% vs. 10.3\%). Thus, to improve fitness, HIIT seems to be an effective strategy for improving health in a short period in overweight/obesity individuals (Gillen and Gibala, 2014; Smith-Ryan et al., 2015). Still, recent studies have suggested that HIIT could be equally, if not more effective, to improve performance and health benefits considerably lower volumes of total working when compared with continuous exercise (Gibala et al., 2006). Comparative studies (continuous moderate intensity vs. intermittent high intensity) show similarities in adaptations imposed. Nikseresht et al. (2014) assessed concentrations of IL-10, IL-20, TNF- $\alpha$, insulin resistance index and aerobic capacity on obese men. Both types of training showed similar effects. Martinez et al. (2015) also observed similar effects between continuous and intermittent training, although pointing that individuals who performed HIIT reported greater satisfaction at the end of training.

\section{CONCLUSIONS}

Physical exercise is an important nonpharmacological treatment for low back pain and obesity. Both MICT and HIIT programs discussed in this review showed similar and beneficial effects for the health-related outcomes. However, some studies showed that individuals who performed HIIT presented greater satisfaction after training completion and better compliance. Moreover, it is interesting to note that HIIT is time-efficient, without reducing its benefits.

Despite the knowledge about health-related benefits of MICT and HIIT, more studies are needed to verify which intervention is more effective particularly for obesity and inflammatory markers associated with low back pain.

\section{CONFLICT OF INTEREST}

No potential conflict of interest relevant to this article was reported.

\section{ACKNOWLEDGMENTS}

Isabela Maia da Cruz Fernandes and Fabio Santos Lira would like to thank the support from Capes and Fapesp SPRINT 2014/ 50672-8.

\section{REFERENCES}

Ahmadizad S, Avansar AS, Ebrahim K, Avandi M, Ghasemikaram M. The effects of short-term high-intensity interval training vs. moderate-intensity continuous training on plasma levels of nesfatin- 1 and inflammatory markers. Horm Mol Biol Clin Investig 2015;21:165-173.

Amirdelfan K, McRoberts P, Deer TR. The differential diagnosis of low back pain: a primer on the evolving paradigm. Neuromodulation 2014;17 Suppl 2:11-17.

Astudillo AM, Balgoma D, Balboa MA, Balsinde J. Dynamics of arachidonic acid mobilization by inflammatory cells. Biochim Biophys Acta 2012;1821:249-256.

Balducci S, Zanuso S, Nicolucci A, Fernando F, Cavallo S, Cardelli P, Fallucca S, Alessi E, Letizia C, Jimenez A, Fallucca F, Pugliese G. Anti-inflammatory effect of exercise training in subjects with type 2 diabetes and the metabolic syndrome is dependent on exercise modalities and independent of weight loss. Nutr Metab Cardiovasc Dis 2010;20:608617.

Briggs AM, Jordan JE, O'Sullivan PB, Buchbinder R, Burnett AF, Osborne $\mathrm{RH}$, Straker LM. Individuals with chronic low back pain have greater difficulty in engaging in positive lifestyle behaviours than those without back pain: an assessment of health literacy. BMC Musculoskelet Disord 2011;12:161.

Briggs MS, Givens DL, Schmitt LC, Taylor CA. Relations of C-reactive protein and obesity to the prevalence and the odds of reporting low back pain. Arch Phys Med Rehabil 2013;94:745-752.

Burke JE, Dennis EA. Phospholipase A2 structure/function, mechanism, and signaling. J Lipid Res 2009;50 Suppl:S237-242.

Chen SM, Liu MF, Cook J, Bass S, Lo SK. Sedentary lifestyle as a risk factor for low back pain: a systematic review. Int Arch Occup Environ Health 2009;82:797-806.

Christiansen T, Paulsen SK, Bruun JM, Pedersen SB, Richelsen B. Exercise training versus diet-induced weight-loss on metabolic risk factors and inflammatory markers in obese subjects: a 12-week randomized intervention study. Am J Physiol Endocrinol Metab 2010;298:E824-831.

Dario AB, Ferreira ML, Refshauge K, Sánchez-Romera JF, Luque-Suarez A, Hopper JL, Ordoñana JR, Ferreira PH. Are obesity and body fat distribution associated with low back pain in women? A population-based study of 1128 Spanish twins. Eur Spine J 2016;25:1188-1195. 
Dario AB, Ferreira ML, Refshauge KM, Lima TS, Ordoñana JR, Ferreira $\mathrm{PH}$. The relationship between obesity, low back pain, and lumbar disc degeneration when genetics and the environment are considered: a systematic review of twin studies. Spine J 2015;15:1106-1117.

Dellaroza MS, Pimenta CA, Duarte YA, Lebrão ML. Chronic pain among elderly residents in São Paulo, Brazil: prevalence, characteristics, and association with functional capacity and mobility (SABE Study). Cad Saude Publica 2013;29:325-334.

Dowd JB, Zajacova A. Long-term obesity and cardiovascular, inflammatory, and metabolic risk in U.S. adults. Am J Prev Med 2014;46:578-584.

Esser N, Paquot N, Scheen AJ. Inflammatory markers and cardiometabolic diseases. Acta Clin Belg 2015;70:193-199.

Ferreira GD, Silva MC, Rombaldi AJ, Wrege ED, Siqueira FV, Hallal PC. Prevalence and associated factors of back pain in adults from southern Brazil: a population-based study. Rev Bras Fisioter 2011;15:31-36.

Galic S, Oakhill JS, Steinberg GR. Adipose tissue as an endocrine organ. Mol Cell Endocrinol 2010;316:129-139.

Garber CE, Blissmer B, Deschenes MR, Franklin BA, Lamonte MJ, Lee IM, Nieman DC, Swain DP; American College of Sports Medicine. American College of Sports Medicine position stand. Quantity and quality of exercise for developing and maintaining cardiorespiratory, musculoskeletal, and neuromotor fitness in apparently healthy adults: guidance for prescribing exercise. Med Sci Sports Exerc 2011;43:13341359.

Gebhardt K, Brenner H, Stürmer T, Raum E, Richter W, Schiltenwolf M, Buchner M. The course of high-sensitive C-reactive protein in correlation with pain and clinical function in patients with acute lumbosciatic pain and chronic low back pain - a 6 months prospective longitudinal study. Eur J Pain 2006;10:711-719.

Gibala MJ, Little JP, Macdonald MJ, Hawley JA. Physiological adaptations to low-volume, high-intensity interval training in health and disease. J Physiol 2012;590:1077-1084.

Gibala MJ, Little JP, van Essen M, Wilkin GP, Burgomaster KA, Safdar A, Raha S, Tarnopolsky MA. Short-term sprint interval versus traditional endurance training: similar initial adaptations in human skeletal muscle and exercise performance. J Physiol 2006;575(Pt 3):901-911.

Gibala MJ, McGee SL. Metabolic adaptations to short-term high-intensity interval training: a little pain for a lot of gain? Exerc Sport Sci Rev 2008; 36:58-63.

Gillen JB, Gibala MJ. Is high-intensity interval training a time-efficient exercise strategy to improve health and fitness? Appl Physiol Nutr Metab 2014;39:409-412.

Gomez I, Foudi N, Longrois D, Norel X. The role of prostaglandin $\mathrm{E}_{2}$ in human vascular inflammation. Prostaglandins Leukot Essent Fatty Acids 2013;89:55-63.
Gray SR, Baker G, Wright A, Fitzsimons CF, Mutrie N, Nimmo MA; Scottish Physical Activity Research Collaboration. The effect of a 12 week walking intervention on markers of insulin resistance and systemic inflammation. Prev Med 2009;48:39-44.

Hawkins M, Belalcazar LM, Schelbert KB, Richardson C, Ballantyne CM, Kriska A. The effect of various intensities of physical activity and chronic inflammation in men and women by diabetes status in a national sample. Diabetes Res Clin Pract 2012;97:e6-8.

Heneweer H, Vanhees L, Picavet HS. Physical activity and low back pain: a U-shaped relation? Pain 2009;143:21-25.

Hoy D, Brooks P, Blyth F, Buchbinder R. The Epidemiology of low back pain. Best Pract Res Clin Rheumatol 2010a;24:769-781.

Hoy D, March L, Brooks P, Woolf A, Blyth F, Vos T, Buchbinder R. Measuring the global burden of low back pain. Best Pract Res Clin Rheumatol 2010b;24:155-165.

Hsu FC, Kritchevsky SB, Liu Y, Kanaya A, Newman AB, Perry SE, Visser M, Pahor M, Harris TB, Nicklas BJ; Health ABC Study. Association between inflammatory components and physical function in the health, aging, and body composition study: a principal component analysis approach. J Gerontol A Biol Sci Med Sci 2009;64:581-589.

Ibrahimi-Kaçuri D, Murtezani A, Rrecaj S, Martinaj M, Haxhiu B. Low back pain and obesity. Med Arch 2015;69:114-116.

Junqueira DR, Ferreira ML, Refshauge K, Maher CG, Hopper JL, Hancock M, Carvalho MG, Ferreira PH. Heritability and lifestyle factors in chronic low back pain: results of the Australian twin low back pain study (The AUTBACK study). Eur J Pain 2014;18:1410-1418.

Langevin HM, Sherman KJ. Pathophysiological model for chronic low back pain integrating connective tissue and nervous system mechanisms. Med Hypotheses 2007;68:74-80.

Lau DC, Dhillon B, Yan H, Szmitko PE, Verma S. Adipokines: molecular links between obesity and atheroslcerosis. Am J Physiol Heart Circ Physiol 2005;288:H2031-2041.

Leggate M, Carter WG, Evans MJ, Vennard RA, Sribala-Sundaram S, Nimmo MA. Determination of inflammatory and prominent proteomic changes in plasma and adipose tissue after high-intensity intermittent training in overweight and obese males. J Appl Physiol (1985) 2012;112:1353-1360.

Libardi CA, De Souza GV, Cavaglieri CR, Madruga VA, Chacon-Mikahil MP. Effect of resistance, endurance, and concurrent training on TNF- $\alpha$, IL-6, and CRP. Med Sci Sports Exerc 2012;44:50-56.

Lin CW, McAuley JH, Macedo L, Barnett DC, Smeets RJ, Verbunt JA. Relationship between physical activity and disability in low back pain: a systematic review and meta-analysis. Pain 2011;152:607-613.

Lira FS, Rosa JC, Lima-Silva AE, Souza HA, Caperuto EC, Seelaender MC, Damaso AR, Oyama LM, Santos RV. Sedentary subjects have 
higher PAI-1 and lipoproteins levels than highly trained athletes. Diabetol Metab Syndr 2010;2:7.

Manchikanti L, Singh V, Falco FJ, Benyamin RM, Hirsch JA. Epidemiology of low back pain in adults. Neuromodulation 2014;17 Suppl 2:3-10.

Martinez N, Kilpatrick MW, Salomon K, Jung ME, Little JP. Affective and enjoyment responses to high-intensity interval training in overweightto-obese and insufficiently active adults. J Sport Exerc Psychol 2015;37: 138-149.

Mikkonen P, Heikkala E, Paananen M, Remes J, Taimela S, Auvinen J, Karppinen J. Accumulation of psychosocial and lifestyle factors and risk of low back pain in adolescence: a cohort study. Eur Spine J 2016; 25:635-642.

Neto JC, Lira FS, de Mello MT, Santos RV. Importance of exercise immunology in health promotion. Amino Acids 2011;41:1165-1172.

Nikseresht M, Agha-Alinejad H, Azarbayjani MA, Ebrahim K. Effects of nonlinear resistance and aerobic interval training on cytokines and insulin resistance in sedentary men who are obese. J Strength Cond Res 2014;28:2560-2568.

Nimmo MA, Leggate M, Viana JL, King JA. The effect of physical activity on mediators of inflammation. Diabetes Obes Metab 2013;15 Suppl 3: 51-60.

Pepys MB, Baltz ML. Acute phase proteins with special reference to C-reactive protein and related proteins (pentaxins) and serum amyloid A protein. Adv Immunol 1983;34:141-212.

Pepys MB, Hirschfield GM. C-reactive protein: a critical update. J Clin Invest 2003;111:1805-1812.

Polak J, Klimcakova E, Moro C, Viguerie N, Berlan M, Hejnova J, Richterova B, Kraus I, Langin D, Stich V. Effect of aerobic training on plasma levels and subcutaneous abdominal adipose tissue gene expression of adiponectin, leptin, interleukin 6, and tumor necrosis factor alpha in obese women. Metabolism 2006;55:1375-1381.

Shiraev T, Barclay G. Evidence based exercise - clinical benefits of high intensity interval training. Aust Fam Physician 2012;41:960-962.

Shiri R, Solovieva S, Husgafvel-Pursiainen K, Telama R, Yang X, Viikari J, Raitakari OT, Viikari-Juntura E. The role of obesity and physical activity in non-specific and radiating low back pain: the Young Finns study.
Semin Arthritis Rheum 2013;42:640-650.

Smith WL, DeWitt DL, Garavito RM. Cyclooxygenases: structural, cellular, and molecular biology. Annu Rev Biochem 2000;69:145-182.

Smith WL, Murphy RC. The eicosanoids: cyclooxygenase, lipoxygenase, and epoxygenase pathways. In: Vance DE, Vance JE, editors. Biochemistry of lipids, lipoproteins and membranes. 6th ed. Amsterdam: Elsevier; 2002. p. 259-296.

Smith-Ryan AE, Melvin MN, Wingfield HL. High-intensity interval training: modulating interval duration in overweight/obese men. Phys Sportsmed 2015;43:107-113.

Stewart Williams J, Ng N, Peltzer K, Yawson A, Biritwum R, Maximova T, Wu F, Arokiasamy P, Kowal P, Chatterij S. Risk factors and disability associated with low back pain in older adults in low- and middle-income countries. Results from the WHO Study on Global AGEing and Adult Health (SAGE). PLoS One 2015;10:e0127880.

Stürmer T, Raum E, Buchner M, Gebhardt K, Schiltenwolf M, Richter W, Brenner H. Pain and high sensitivity C-reactive protein in patients with chronic low back pain and acute sciatic pain. Ann Rheum Dis 2005;64:921-925.

Sugimoto Y, Narumiya S. Prostaglandin E receptors. J Biol Chem 2007; 282:11613-11617.

Teichtahl AJ, Urquhart DM, Wang Y, Wluka AE, O'Sullivan R, Jones G, Cicuttini FM. Physical inactivity is associated with narrower lumbar intervertebral discs, high fat content of paraspinal muscles and low back pain and disability. Arthritis Res Ther 2015;17:114.

Weston KS, Wisløff U, Coombes JS. High-intensity interval training in patients with lifestyle-induced cardiometabolic disease: a systematic review and meta-analysis. Br J Sports Med 2014;48:1227-1234.

Woodward DF, Jones RL, Narumiya S. International Union of Basic and Clinical Pharmacology. LXXXIII: classification of prostanoid receptors, updating 15 years of progress. Pharmacol Rev 2011;63:471-538.

Zanuto EA, Codogno JS, Christófaro DG, Vanderlei LC, Cardoso JR, Fernandes RA. Prevalence of low back pain and associated factors in adults from a middle-size Brazilian city. Cien Saude Colet 2015;20: 1575-1582. 